\title{
Oceanic processes associated with anomalous events in the Indian Ocean with relevance to 1997-1998
}

\author{
Raghu Murtugudde \\ Earth System Science Interdisciplinary Center, University of Maryland, College Park \\ Julian P. McCreary Jr. \\ International Pacific Research Center, University of Hawaii, Honolulu
}

Antonio J. Busalacchi

Laboratory for Hydrospheric Processes, NASA Goddard Space Flight Center, Greenbelt, Maryland

\begin{abstract}
An anomalous climatic event occurred in the Indian Ocean (IO) region during 1997-1998, which coincided with a severe drought in Indonesia and floods in parts of eastern Africa. Cool sea surface temperature anomalies (SSTAs) were present in the eastern IO along and south of the equator. Beginning in July 1997, warm SSTAs appeared in the western IO, and they peaked in February 1998. An ocean general circulation model is employed to investigate the dynamic and thermodynamic processes that caused the SSTAs associated with this and other similar IO events. The eastern cooling resulted from unusually strong upwelling along the equator and Sumatra. The Sumatran upwelling was forced both locally by the stronger alongshore winds and remotely by equatorial and coastal Kelvin waves. By the end of 1997, weakening of the winds and the associated reduction in latent heat loss led to the elimination of the cold SST anomalies in the east. The western warming was initiated by weaker Southwest Monsoon winds and maintained by enhanced precipitation forcing, which resulted in a barrier layer structure. Analysis of the mixed layer temperature equation indicates that a downwelling Rossby wave contribution was crucial for sustaining the warming into February 1998. It is tempting to suppose that the 1997 event was related to the El Niño-Southern Oscillation (ENSO) event that took place in the Pacific at the same time. Indeed, weaker IO events occur quite regularly in the control run that evolve similarly to the 1997 event, and they are often but not always related to ENSO. We speculate that these events represent a natural mode of oscillation in the IO, which is externally forced by ENSO but also excited by ocean-atmosphere interactions internal to the IO.
\end{abstract}

\section{Introduction}

An extreme climatic event took place in the Indian Ocean (IO) during 1997 and early 1998. It was associated with the second-largest sea surface temperature anomalies (SSTAs) occurring in the region during the past half century. Plate 1a illustrates the time development of observed SSTAs along the equator during the event. In the late spring of 1997 a surface warming ensued over the western region. (Throughout this paper, seasons always refer to those in the Northern Hemisphere.) It peaked in February 1998, by which time it had spread across most of the tropical IO.

Strong cooling was evident in the eastern ocean by September 1997, and it continued into January 1998. As a consequence of these changes, there was an equatorial SST gradient from east to west, a reversal of the climatological situation. The wind stress field was also highly unusual during the fall, with easterlies along the equator replacing the climatological westerlies (Plate 2a) and strengthened alongshore winds off Copyright 2000 by the American Geophysical Union.

Paper number 1999JC900294.

0148-0227/00/1999JC900294\$09.00
Sumatra. As the western warming continued, anomalous convection and rainfall over eastern Africa and the western Indian Ocean developed and persisted [Birkett et al., 1999].

It is reasonable to suppose that this remarkable IO event was related to the El Niño-Southern Oscillation (ENSO) event that took place at the same time in the Pacific. In fact, a number of similar but weaker IO events occurred during the past 40 years that are also related to ENSO (see the discussion in section 3.3). On the other hand, the ENSO connection is not exact. For example, the largest IO event during the same time interval took place in 1961, which is not recognized as an ENSO year [Reverdin et al., 1986].

In this paper we utilize an oceanic general circulation model (OGCM) to investigate the dynamics and thermodynamics of such IO events during the past 40 years, focussing on the 1997 extreme event. Specifically, we first identify the basic processes that caused warm and cold SSTAs during the 1997 event. Then we demonstrate that other weaker IO events evolved similarly. This similarity indicates that they represent a natural mode of oscillation in the IO, one that is easily excited in a variety of ways. We note that it appears to be externally forced by ENSO and speculate that it is also generated by ocean-atmosphere interactions internal to the IO. 

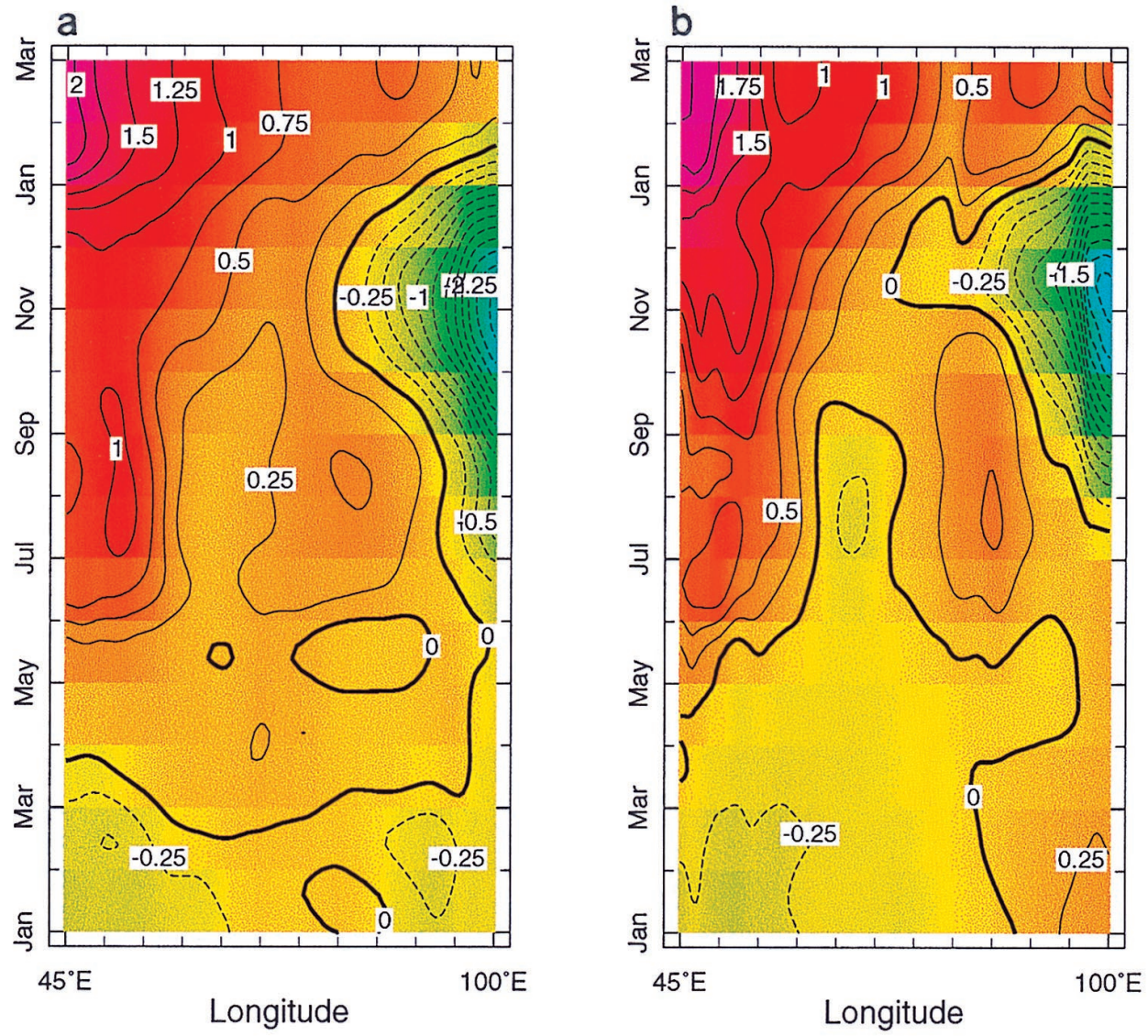

SSTA (Reynolds)

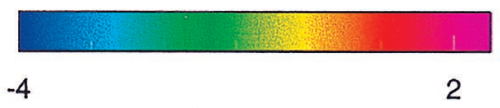

SSTA-Model

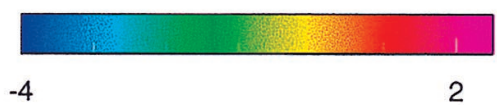

Plate 1. Anomolous sea surface temperatures (SSTs) (the contour interval is $0.25^{\circ} \mathrm{C}$ ) along the equator during 1997-1998 for the (a) Reynolds SST and (b) control run. The model was driven with interannual winds and precipitation but climatological radiation and cloudiness.

\section{Model Ocean}

The ocean model is a reduced gravity primitive equation OGCM confined to the IO region north of $30^{\circ} \mathrm{S}$. It consists of 19 sigma coordinate layers beneath a variable thickness surface mixed layer [Chen et al., 1994]. Surface heat fluxes are determined by coupling a simple model of the atmospheric boundary layer to the OGCM, and freshwater forcing is included as a natural boundary condition. Model details are presented by Murtugudde et al. [1996, 1998a] and Murtugudde and Busalacchi [1999]. Model salinity, temperature, and layer thicknesses are relaxed to Levitus [1994] data from $30^{\circ}$ to $25^{\circ} \mathrm{S}$ at the southern boundary. For our control run the model is almost always forced by $10 \mathrm{~m}$ winds and surface precipitation from National Centers Environmental Prediction (NCEP) reanalyses [Kalnay et al., 1996] for the period from January 1958 to March 1998. The exception is for the period from October 1997 to February 1998, when the NCEP wind stress was reduced by $20 \%$ in the Somali Jet region $\left(50^{\circ}-70^{\circ} \mathrm{E}, 0^{\circ}-20^{\circ} \mathrm{N}\right)$ and also along the equator (from $5^{\circ} \mathrm{S}$ to $5^{\circ} \mathrm{N}$ ) after they were found to be too strong compared to Special Sensor Microwave Imager (SSMI) wind products. In addition, for the period mentioned above the gustiness parameter, which accounts for latent heat loss due to high-frequency wind forcing (diurnal to weekly), had to be set to $0.5 \mathrm{~m} \mathrm{~s}^{-1}$ for regions with low wind speeds (see Plate 5), whereas it is normally set to $4.5 \mathrm{~m} \mathrm{~s}^{-1}$ over the whole basin [Murtugudde and Busalacchi, 1998]. The reduced minimum wind speed was important for simulating the dissipation of cold SSTAs in the east, and the reduction in wind stresses allowed accurate simulation of warming in the west.

Because of a lack of sufficiently long time series of reliable cloudiness and solar radiation data, climatological Earth Radiation Budget Experiment (ERBE) radiation and International Satellite Cloud Climatology Project (ISCCP) cloudiness are used in the interannual simulations to determine surface heat fluxes [also see Murtugudde et al., 1996, 1998a]. Wind speed for the latent and sensible heat fluxes is computed from the interannual wind stresses assuming a drag coefficient of 0.0015 . We also obtained a solution forced by climatological precipitation, wind stresses, and wind speed, and throughout the text we refer to it as the "climatological solution."

It is well known that there are inaccuracies in the available atmospheric forcing fields. To investigate effects due to these inaccuracies, we also obtained a number of test experiments driven by different products. There are significant differences 


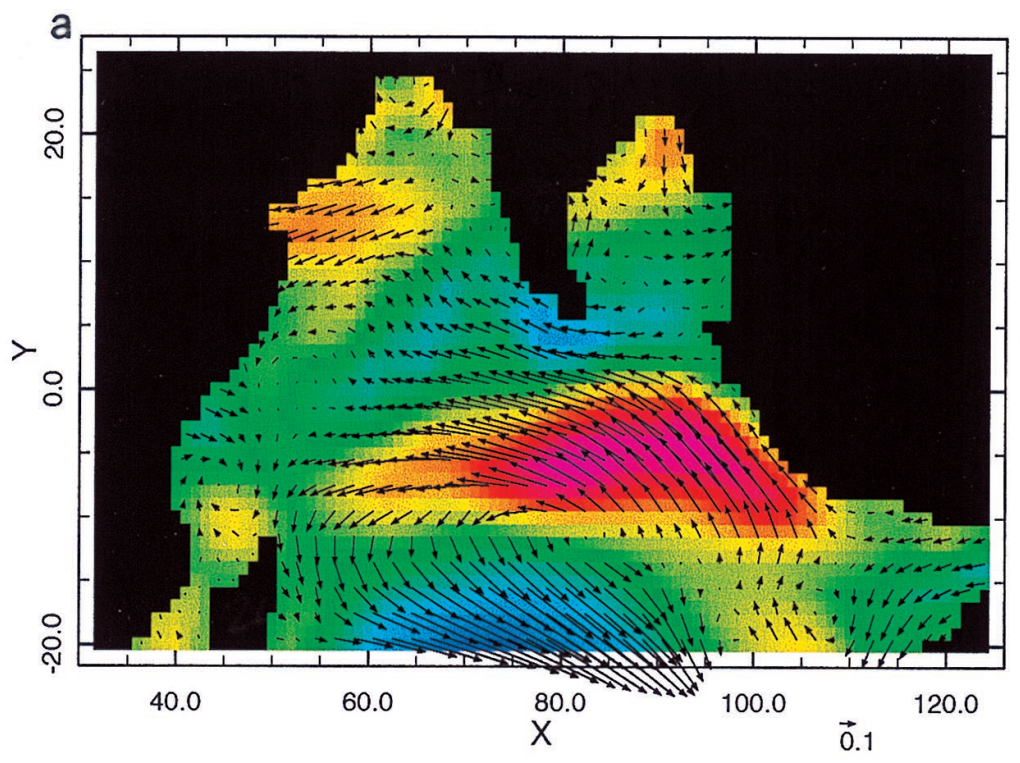

SPDA,TXA,TYA_97
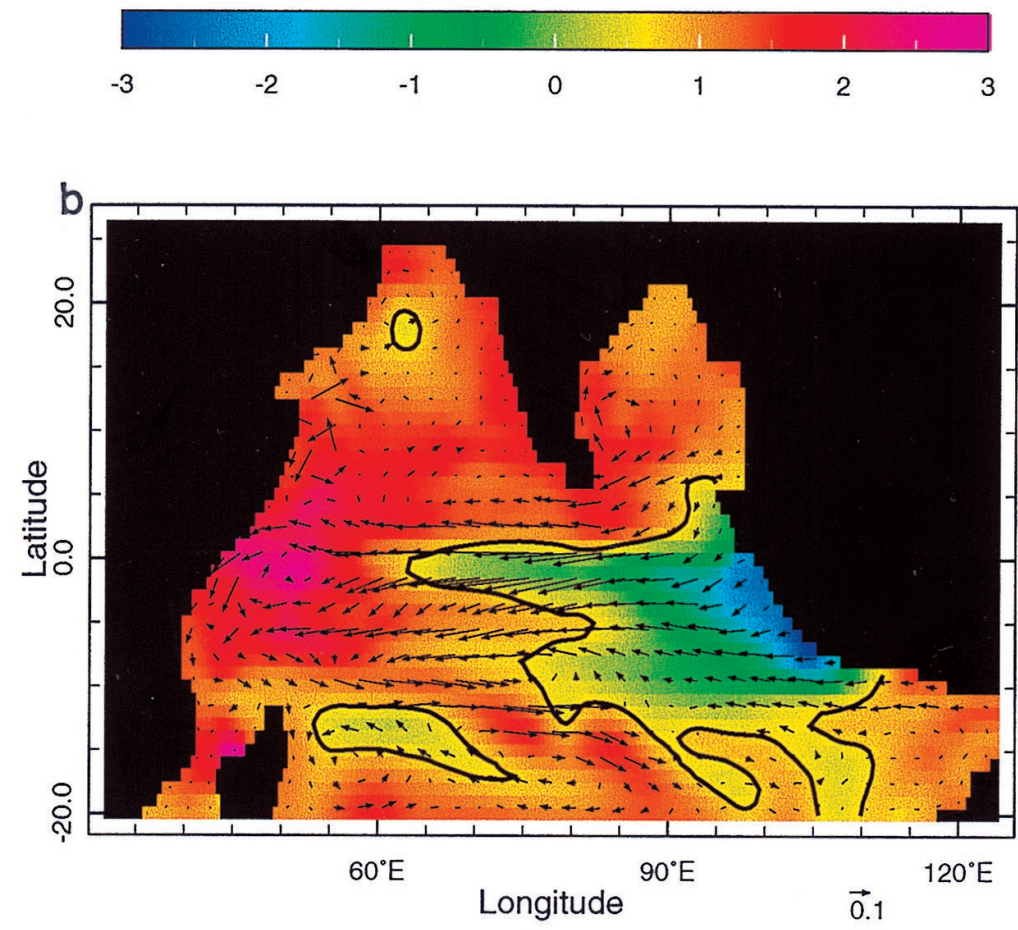

SSTA, (ua,va):OND97

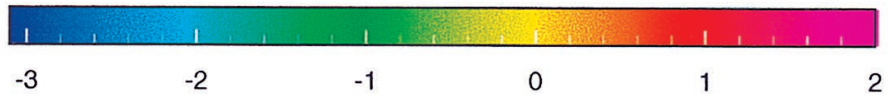

Plate 2. Anomalous fields during October-December 1997 showing (a) National Centers for Environmental Prediction (NCEP) wind stress vectors $\left(\right.$ dynes $\mathrm{cm}^{-2}$ ) overlying wind speed anomalies $\left(\mathrm{m} \mathrm{s}^{-1}\right)$ and (b) surface current vectors $\left(\mathrm{m} \mathrm{s}^{-1}\right)$ over SST (degrees Celsius) for the control run. The thick line corresponds to the $0^{\circ} \mathrm{C}$ contour.

among the solutions. For example, in a run forced by Florida State University (FSU), winds for 1997-1998 SSTAs were cooler by $0.6^{\circ} \mathrm{C}$ in the western ocean, and off Sumatra they were colder by as much as $3^{\circ} \mathrm{C}$ because of much stronger coastal upwelling there. When the ISCCP radiation climatology was employed instead of ERBE data, the eastern equato- rial IO was warmer by $\sim 0.8^{\circ} \mathrm{C}$ during April 1998 [also see Murtugudde and Busalacchi, 1999]. With forcing by interannual precipitation (both NCEP and Xie and Arkin [1996] data produced similar results), SSTAs were cooler by $0.6^{\circ} \mathrm{C}$ in the eastern ocean and warmer by $0.5^{\circ} \mathrm{C}$ in the west: lower precipitation in the east during fall 1997 facilitates easier erosion of 


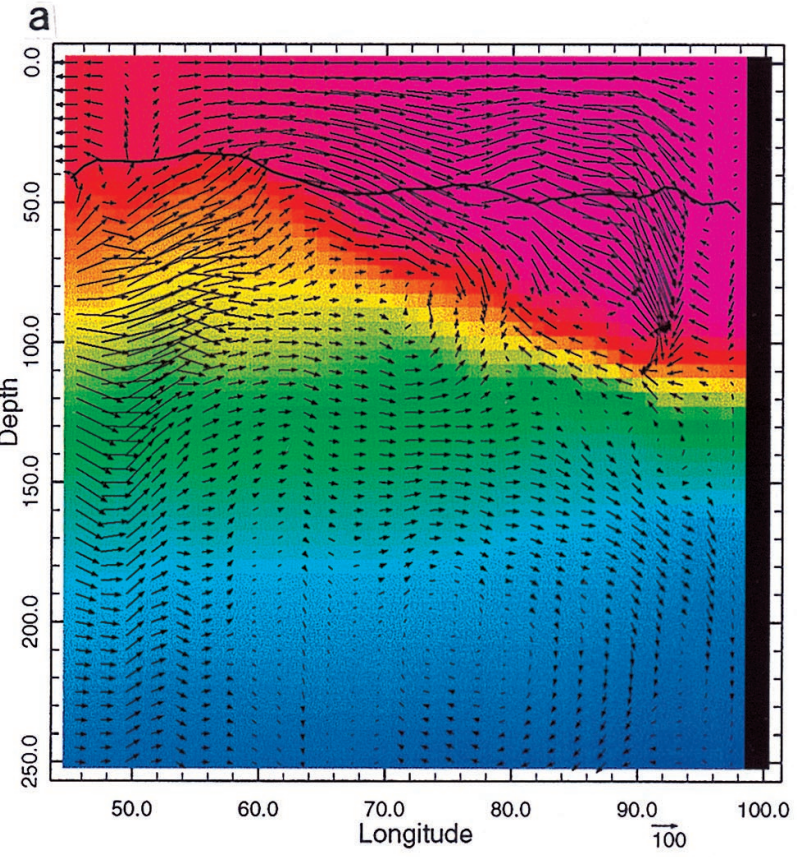

TZO_Clim

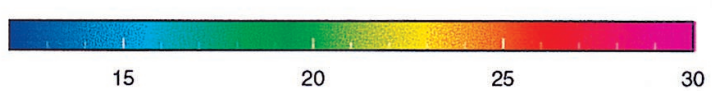

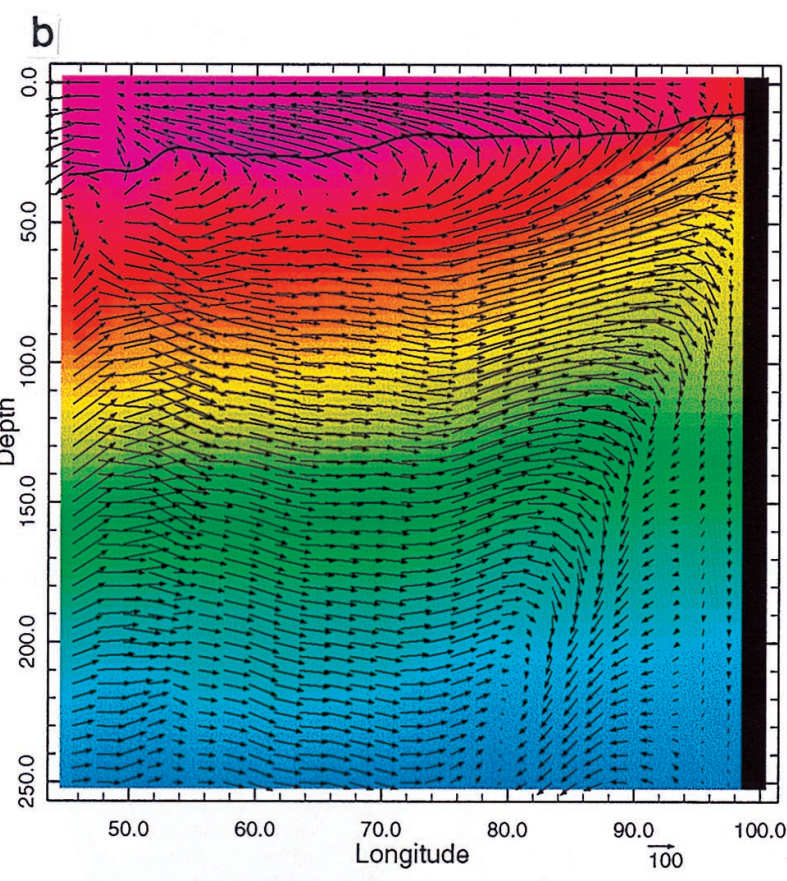

TZO_97

Plate 3. Equatorial sections averaged from October through December showing temperatures (color) and zonal and vertical current vectors for (a) the climatological simulation and (b) the control run for 1997. Solid lines indicate the bottom of the mixed layer.

the barrier layer and enhanced cooling; higher precipitation in the west leads to a freshwater lens, a shallower mixed layer, and warmer SSTs. Despite these differences the general pattern of the responses was consistent among all the solutions. Given this consistency, we believe that our control run is sufficiently accurate to capture the dominant physics of the event.

\section{Results}

In this section we first describe the 1997-1998 event in our control run (section 3.1) and discuss the dynamic and thermodynamic processes that account for its prominent SSTAs (section 3.2). Then we note that weaker events occur regularly and have a similar structure to the 1997 event (section 3.3).

\subsection{Description}

3.1.1. SST anomalies. Observed (Plate 1a) and modeled (Plate 1b) SSTAs along the equator for 1997-1998 are contrasted. The modeled SSTA is able to reproduce the basinscale features of the event (i.e., eastern cooling and western warming), albeit with some notable differences from the observed SSTA. In the east, coldest SSTAs occur in November close to the eastern boundary, consistent with the observations, but the minimum is warmer by $0.75^{\circ} \mathrm{C}$. In the west the model's SSTAs are slightly warmer in the fall but cooler in the winter, especially during January-February 1998. These discrepancies may be partly due to inaccuracies in the forcing fields (section 2) and partly due to deficiencies in the model's thermal structure. For example, the cooling in reality may have been enhanced by the reduced solar heating in the east caused by the smoke from Indonesian fires during this period [Murtugudde et al., 1999], which has not been accounted for in our simulation.

Plate 2b illustrates the horizontal structure of SST (color) and surface current (vectors) anomalies for the control run. Prominent features are cold SSTAs throughout the eastern IO on and south of the equator and a v-shaped pattern of warm SSTAs with its apex in the western IO and branches extending northeastward and southeastward. The eastern cooling is strongest at the eastern boundary and appears to be advected westward along the equator via the anomalous currents (a property that is verified in section 3.2).

3.1.2. Vertical structure. Plate 3 shows equatorial sections of model temperatures and currents averaged from October through December (OND) for the control run (Plate 3b) and for the climatological solution (Plate $3 \mathrm{a}$ ). The solid curves designate the bottom of the mixed layer. The thermal structure is strikingly different between the two solutions. In the climatological case the thermocline slopes down from west to east, attaining a depth of $\sim 100 \mathrm{~m}$ at the eastern boundary. The mixed layer thickness, however, remains at $\sim 50 \mathrm{~m}$, so that there is a significant barrier layer in the east [Lukas and Lindstrom, 1991]. In contrast, for 1997 the situation is reversed by the anomalous easterlies. In this case the thermocline slopes upward from west to east, and there is a significant barrier layer in the west. The mixed layer is $\sim 35 \mathrm{~m}$ deep in the west and has reached a minimum specified thickness of $10 \mathrm{~m}$ in the east.

In the climatological solution there is an eastward current in the upper $50 \mathrm{~m}$ almost everywhere, the exception being in the Somali Current region near the west coast. This flow, the 
solution's fall Wyrtki Jet, is driven by westerly winds that typically peak in November. The flow in the thermocline is weakly eastward, and there is little indication of upwelling into the mixed layer. In contrast, during the fall of 1997 the nearsurface flow is completely reversed, the eastward flow in the thermocline is much stronger, and there is upwelling into the mixed layer almost everywhere along the section. Thus the vertical structure during fall 1997 is quite similar to those in the equatorial Pacific and Atlantic Oceans, in which a surface South Equatorial Current (SEC) and a subsurface Equatorial Undercurrent (EUC) are forced by equatorial easterly winds.

\subsection{Processes}

We utilize the model's mixed layer temperature equation to define quantitative measures of the process anomalies that determine SSTAs. That equation is

$$
T_{1 t}=Q / h_{1}-u_{1} T_{1 x}-v_{1} T_{1 y}+w_{1}^{+}\left(T_{2}-T_{1}\right) / h_{1}+k_{t} \nabla^{2} T_{1},
$$

where $T_{1}, h_{1}$, and $v_{1}$ are mixed layer temperature, thickness, and velocity, respectively, $Q$ is the surface heat flux, $w_{1}^{+}$is the entrainment velocity, and $k_{t}$ is the Laplacian mixing coefficient. Each term on the right-hand of (1) measures the influence of a particular process, namely (from left to right), surface heating 2 , zonal advection $\mathcal{U}$, meridional advection $\mathscr{V}$, entrainment cooling $\mathcal{W}$, and mixing; the term on the left-hand side measures temperature tendency $\mathcal{T}$. Areal averages of the anomalies of individual terms then provide measures of the processes governing the temperature variability. In the following we report anomalies of $\mathcal{2}, \mathcal{U}, \mathscr{V}$, and $\mathscr{W}$ in order to show their relative importance in determining SSTA. Anomalies are computed for each month by subtracting their climatological values computed over 1982-1998.

3.2.1. Eastern cooling. Figure 1 shows model and Reynolds SSTAs in three areas of the eastern IO: along the equator in the interior ocean $\left(75^{\circ}-85^{\circ} \mathrm{E}, 5^{\circ} \mathrm{S}-5^{\circ} \mathrm{N}\right)$, in the eastern equatorial region adjacent to the coast of Sumatra $\left(85^{\circ}-95^{\circ} \mathrm{E}, 5^{\circ} \mathrm{S}-\right.$ $\left.5^{\circ} \mathrm{N}\right)$, and in the coastal upwelling region off Java $\left(95^{\circ}-105^{\circ} \mathrm{E}\right.$, $\left.10^{\circ} \mathrm{S}-0^{\circ} \mathrm{N}\right)$. In each region, model SSTAs differ from Reynolds SSTAs by $<0.5^{\circ} \mathrm{C}$. These differences are most likely related to the fact that we use climatological radiation and cloudiness. It is also possible that the model pycnocline shoaled excessively because of strong alongshore winds, thereby strengthening cooling due to entrainment in the solution. Note that the SSTA variations in all three regions have similar structures, with periods of summertime warming followed by cooling during the fall and warming during the winter. They differ, however, in the strengths of the warming and cooling events, the summertime warming being strongest along the equator (Figure 1a) and the cooling strongest in the coastal upwelling region (Figure 1c).

To identify the causes of these anomalies, Figure 2 shows curves of process anomalies in the three regions. In each region the wintertime warming is caused by $Q$ being large and positive, the other terms all being negative at that time. In the coastal upwelling region the increase in $Q$ is largely a reaction to the drop in SST, which lowers the latent heat loss from the ocean. In the other two regions, when SSTAs are significantly positive, they are caused by weakened latent heat loss due to anomalously low wind speeds (see Plate 5). The winter warming in the coastal upwelling region was also facilitated by the shallowing of the mixed layer by as much as $20 \mathrm{~m}$, which allowed the SST to warm particularly rapidly.
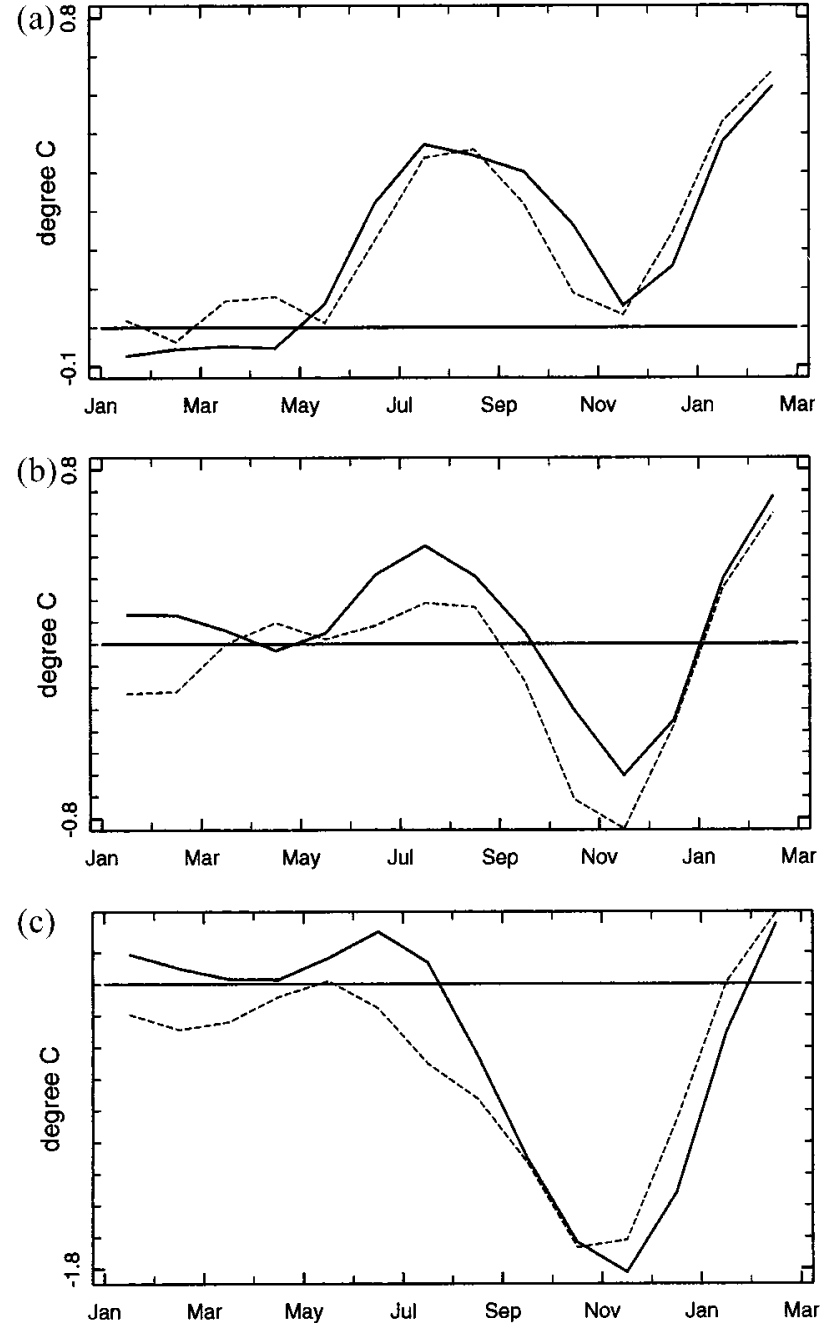

Figure 1. Model (solid) and Reynolds (dashed) SST anomalies averaged over (a) $75^{\circ}-85^{\circ} \mathrm{E}, 5^{\circ} \mathrm{S}-5^{\circ} \mathrm{N}$; (b) $85^{\circ}-95^{\circ} \mathrm{E}, 5^{\circ} \mathrm{S}-$ $5^{\circ} \mathrm{N}$; and (c) $95^{\circ}-105^{\circ} \mathrm{E}, 10^{\circ} \mathrm{S}-0^{\circ} \mathrm{N}$.

The fall cooling has different causes in each region. As expected, in the two coastal regions (Figures $2 \mathrm{~b}$ and $2 \mathrm{c}$ ), entrainment cooling $\mathcal{W}$ is a prominent cause. Off Java (Figure $2 c)$, meridional advection anomalies $\mathscr{V}$ also contribute significantly: cold SSTAs appear first off the Java coast in the southeast, and they are subsequently advected northwestward along the coast. Note that during normal years the fall season is dominated by the Wyrtki Jet and the advection is southeastward. In contrast, in the interior equatorial region (Figure 2a), westward advection of cold waters $\boldsymbol{u}$ by the anomalous westward jet was the dominant cooling process, as is evident by the equatorial tongue of cool SSTAs in Plate 2. The cooling in both equatorial regions (Figures $2 \mathrm{a}$ and $2 \mathrm{~b}$ ) is also enhanced by a period of negative $Q$ during the summer and fall. It is caused by the increased easterlies, which intensify the latent heat loss from the ocean, and it lasts until SSTAs decrease, thereby weakening the heat loss.

The large summertime warming in the interior equatorial region results from positive $Q, \mathcal{W}$, and $\mathscr{V}$ anomalies that counteract the cooling effect of $\mathcal{U}$. The initial increase in $Q$ is due to weaker winds and reduced latent heat loss, and it continues until the increased SST and stronger easterlies enhance latent 

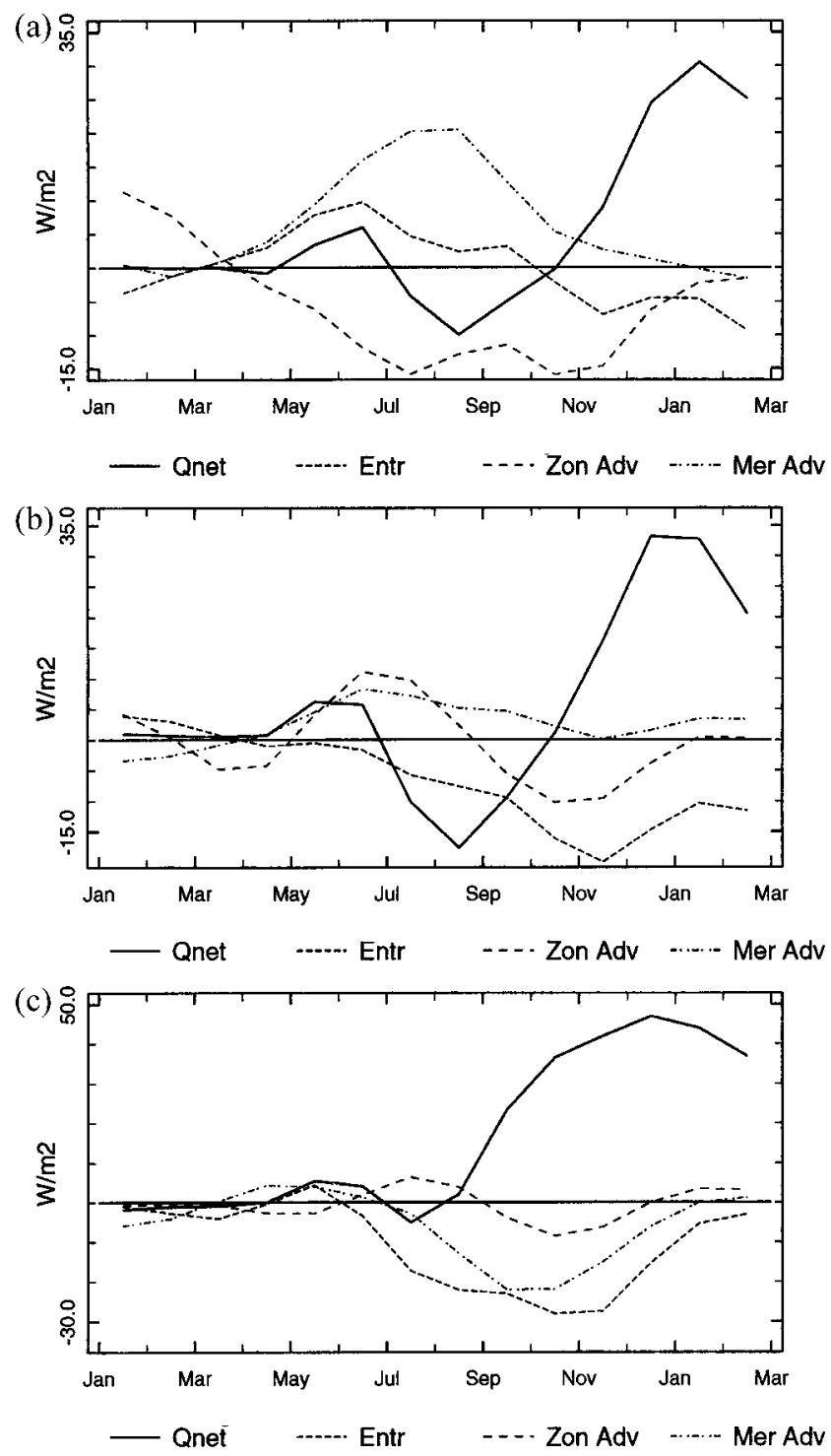

Figure 2. Anomalies of net heat flux, entrainment, and zonal and meridional advection for the mixed layer averaged over (a) $75^{\circ}-85^{\circ} \mathrm{E}, 5^{\circ} \mathrm{S}-5^{\circ} \mathrm{N}$; (b) $85^{\circ}-95^{\circ} \mathrm{E}, 5^{\circ} \mathrm{S}-5^{\circ} \mathrm{N}$; and (c) $95^{\circ}-105^{\circ} \mathrm{E}$, $10^{\circ} \mathrm{S}-0^{\circ} \mathrm{N}$. All three eastern regions are dominated by entrainment cooling during fall 1997. Weaker winds and reduced latent heat loss lead to rapid increase in net surface heat flux and warm SST anomalies by early 1998.

cooling. The largest warming process, however, is due to $\mathscr{V}$. The meridional velocity in this region $\left(75^{\circ}-85^{\circ} \mathrm{E}, 5^{\circ} \mathrm{S}-5^{\circ} \mathrm{N}\right)$ increased from near zero in January 1997 to nearly $3 \mathrm{~cm} \mathrm{~s}^{-1}$ by May on both sides of the equator and remained positive till July 1997. SST anomalies increased from negative to the south of $2^{\circ} \mathrm{S}$ to positive to the north of the equator till July. By August, positive SSTA occupied the entire box. This led to a rapid increase in $\mathscr{V}$ till August 1997, as seen in Figure 2a. Zonal current anomalies were negative from January through July 1997. Thus positive $\mathscr{V}$ was being compensated by $\mathcal{U}$ in the eastern equatorial box. As the easterlies strengthened and eastern cooling ensued, the SSTs and $\mathscr{V}$ began to drop from September 1997.

The preceding analysis of terms in (1) is not able to assess the relative importance of equatorial versus alongshore wind
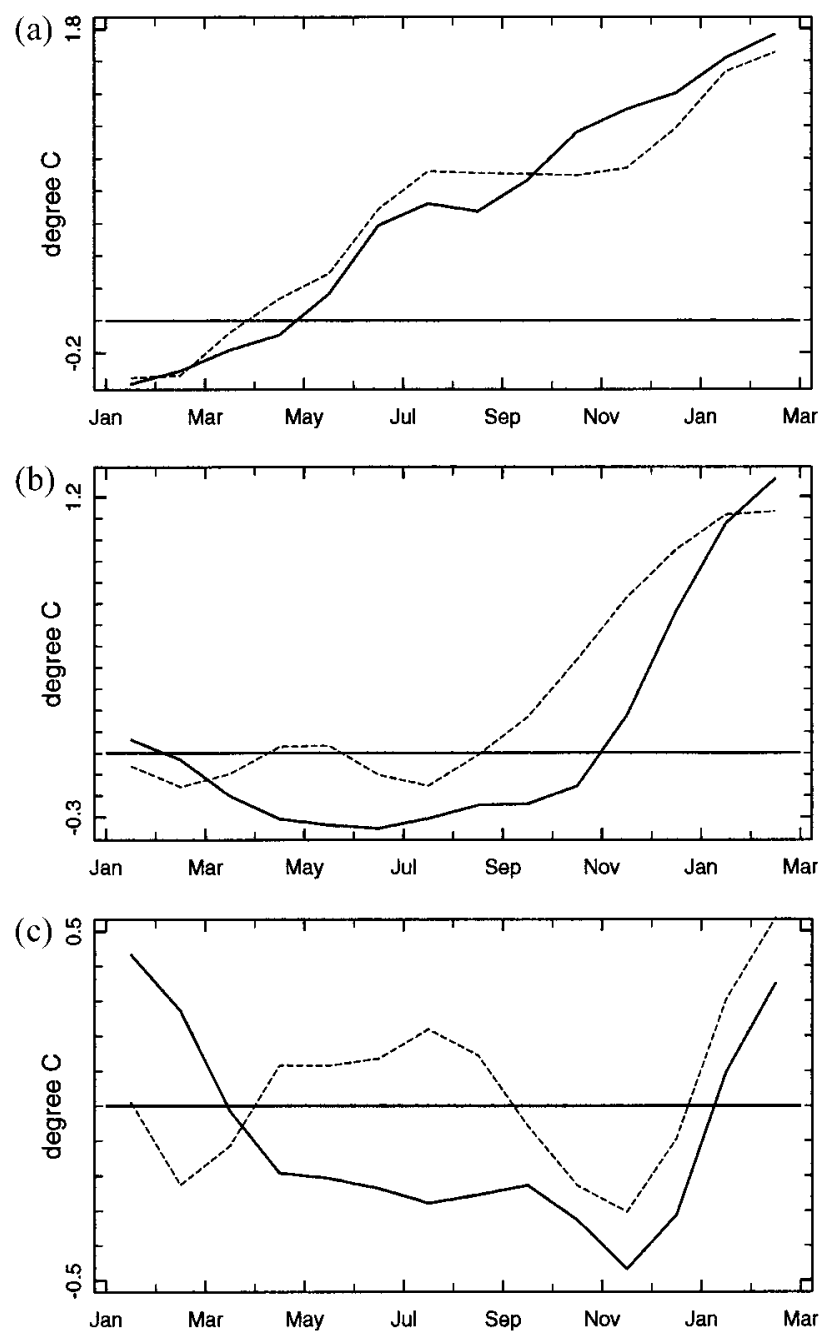

Figure 3. Model (solid) and Reynolds (dashed) SST anomalies averaged over (a) $45^{\circ}-55^{\circ} \mathrm{E}, 5^{\circ} \mathrm{S}-5^{\circ} \mathrm{N}$; (b) $60^{\circ}-70^{\circ} \mathrm{E}, 15^{\circ}-$ $5^{\circ} \mathrm{S}$; and (c) $85^{\circ}-95^{\circ} \mathrm{E}, 15^{\circ}-5^{\circ} \mathrm{S}$. Warming of the southern tropical Indian Ocean (Figures $3 \mathrm{~b}$ and $3 \mathrm{c}$ ) in the model is delayed by over a month compared to in Reynolds SST.

anomalies in driving the upwelling off Sumatra. To do this, we performed test runs in which the interannual variability of the winds was separately suppressed both east and west of $90^{\circ} \mathrm{E}$. In the test without interannual forcing east of $90^{\circ} \mathrm{E}$ the maximum cooling off Sumatra decreased by $40 \%$ from its value in the control run, whereas in the other test it decreased by $25 \%$. These results indicate that both local and remote anomalous forcing enhanced the Sumatran upwelling roughly equally. The anomalous equatorial easterlies generate equatorial and coastal Kelvin waves that raise the thermocline and thin the barrier layer off Sumatra (as in Plate 3); hence the cooling due to upwelling driven by the local alongshore winds is enhanced because cooler water is entrained into the mixed layer. The TOPEX data for fall 1997 clearly show upwelling equatorial Kelvin waves [Murtugudde et al., 1998b].

3.2.2. Western and southern warming. To analyze the warming during the event, we selected three representative regions: a western equatorial region $\left(45^{\circ}-55^{\circ} \mathrm{E}, 5^{\circ} \mathrm{S}-5^{\circ} \mathrm{N}\right)$, which underwent the maximum warming, and the western $\left(60^{\circ}-70^{\circ} \mathrm{E}, 15^{\circ}-5^{\circ} \mathrm{S}\right)$ and eastern $\left(85^{\circ}-95^{\circ} \mathrm{E}, 15^{\circ}-5^{\circ} \mathrm{S}\right)$ parts of the southern tropical Indian Ocean. Figures 3 and 4 show 

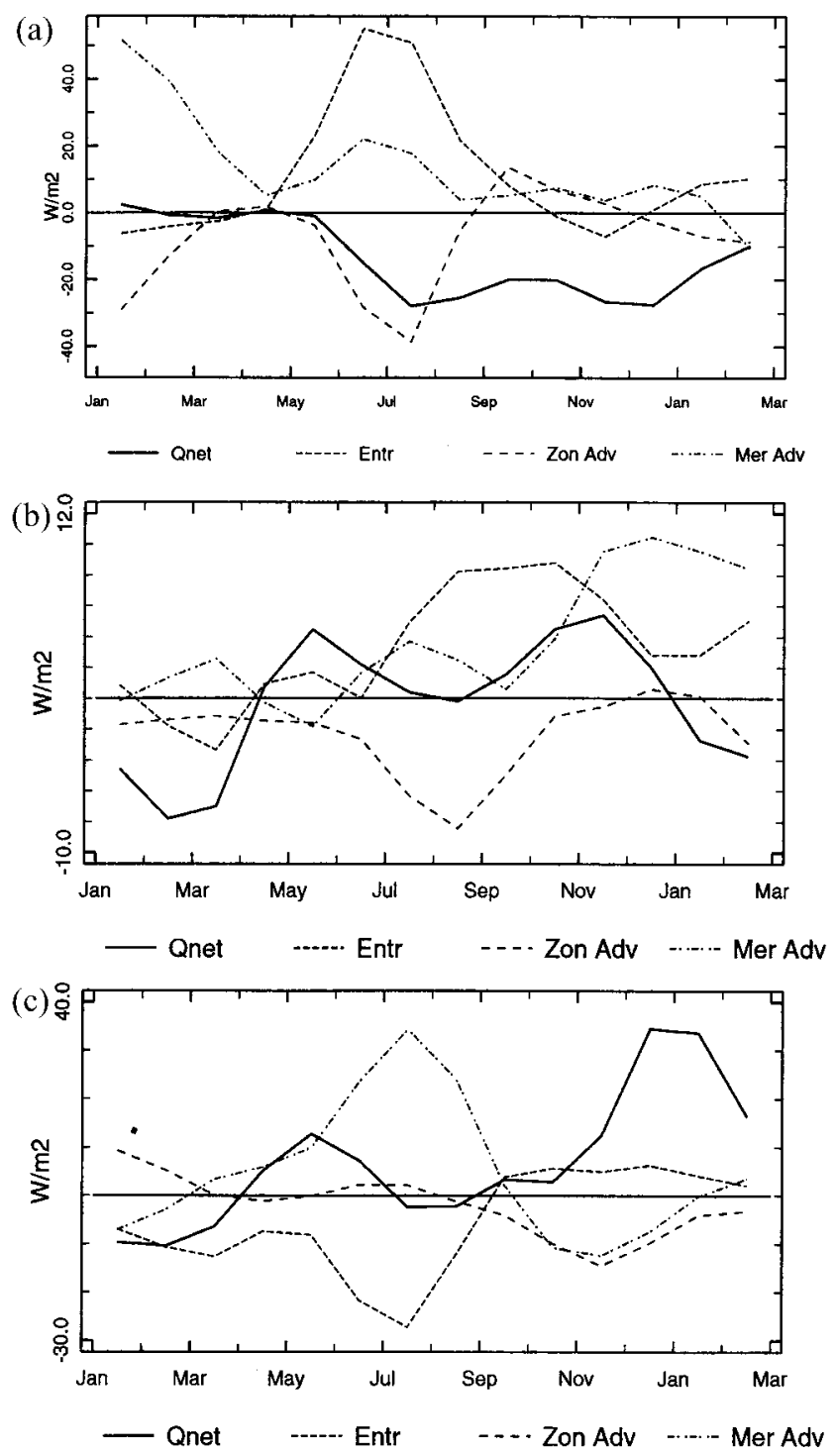

Figure 4. Anomalies of net surface heat flux, entrainment, and zonal and meridional advection terms averaged over (a) $45^{\circ}-55^{\circ} \mathrm{E}, 5^{\circ} \mathrm{S}-5^{\circ} \mathrm{N}$; (b) $60^{\circ}-70^{\circ} \mathrm{E}, 15^{\circ}-5^{\circ} \mathrm{S}$; and (c) $85^{\circ}-95^{\circ} \mathrm{E}$, $15^{\circ}-5^{\circ} \mathrm{S}$. Figure $4 \mathrm{a}$ also shows the anomaly of the rate of SST change (see (1)).

SSTAs and the process anomalies in each of the regions. We have included the southeastern region $\left(85^{\circ}-95^{\circ} \mathrm{E}, 15^{\circ}-5^{\circ} \mathrm{S}\right)$ here although it experienced mild cooling during fall 1997 and warmed only slightly during early 1998 .

3.2.2.1. Equatorial region: In the equatorial region, SSTAs rose steadily throughout the event (Figure 3a). This rise is generally consistent with the SSTA response determined from Reynolds SST, except that the latter remained nearly constant for July-October 1997 and then rapidly increased from November 1997 to February 1998.

The corresponding process anomalies are shown in Figure 4a. Interestingly, throughout the record, $Q$ only provides cooling, a consequence of increased latent cooling due to the warm SSTAs. The $\mathscr{V}$ and $\mathscr{U}$ anomalies contributed to the initial warming. Between May and September, anomalous $\mathscr{V}$ and $\mathscr{U}$ were nearly equal and opposite in sign, and so, the anomalous warming was due primarily to $\mathcal{W}$. The reduced rate of warming in July and August coincides with a deepening of the mixed layer and increased entrainment cooling that lowered $\mathcal{W}$. Note that there are no large warming terms during the fall and winter months despite the fact that the SSTA curve continued to increase steadily. During this period then a significant contributor to the temperature balance is the horizontal mixing term in (1).

The contribution of waves to SSTA cannot be determined from our analysis of terms in (1). Both model and TOPEX/ Poseidon data, however, show that a downwelling Rossby wave arrived at the western coast in the equatorial region during December 1997 (Plate 4). This Rossby wave was actually part of a packet that was centered on $8^{\circ} \mathrm{S}$ [Murtugudde et al., 1998b]. It warmed the western equatorial IO primarily by deepening the pycnocline, both directly and indirectly via reflection of coastal and equatorial Kelvin waves from the western boundary, thereby decreasing entrainment cooling. This effect is shown in Figure 4a by the rise in $W$. Model sea level anomalies, however, are nearly $40 \%$ weaker than TOPEX/Poseidon data, and there are also differences in the Rossby wave phase speed, as seen in Plate 4. Thus the model probably fails to produce a sufficiently deep thermocline during late 1997 and so underestimates the role of the decreased entrainment cooling during January-February 1998.

3.2.2.2. Southern region: The southern tropical IO also warmed by over $1^{\circ} \mathrm{C}$ (Figure $3 \mathrm{~b}$ ) in the west and by over $0.5^{\circ} \mathrm{C}$ in the east (Figure 3c) during the late fall and winter in both the model and the observations. In the western region (Figure 3b), though, warming in the model occurs after October 1997, more than 2 months later than warming in the Reynolds SST. It is not clear what accounts for this discrepancy. Note that the model SSTAs are colder than Reynolds in both the southern tropical boxes. It is possible that lack of the Indonesian Throughflow leads to a shallower thermocline and hence intensified entrainment cooling in the model, resulting in the solution being too cold throughout the summer. Earlier in the record, observed and modeled SSTAs also disagree in the eastern region (Figure 3c), but that is to be expected since the amplitudes of the SSTAs there are so small $\left(<0.3^{\circ} \mathrm{C}\right)$.

Interestingly, the causes of the fall and winter warmings are different in the two regions. In the eastern region (Figure 4c) it is almost entirely due to increased $Q$, which is caused by weakening winds and reduced latent heat loss. In the western region (Figure $4 \mathrm{~b}$ ) the warming results from $Q, \mathcal{W}$, and $\mathscr{V}$. Reduced $\mathcal{W}$ dominates the west (Figure 4b) from June through November 1997, which is, again, related to weaker winds and associated mixed layer changes. The $u$ anomalies generate slightly negative SSTAs in the model until November. At these latitudes the Indonesian Throughflow has the largest effect on zonal currents, which is not accounted for in our simulations. The warming in the model after November is caused by a reduction in $\mathscr{U}$, enhanced warming due to $\mathscr{V}$, and increased 2. The meridional velocity was positive between May and November 1997 in the western box and between January and July 1997 in the eastern box, explaining the patterns of $\mathscr{V}$ in Figures $4 \mathrm{~b}$ and $4 \mathrm{c}$. Latent heat loss and $\mathcal{W}$ start to increase from December onward because of the increased southeasterlies seen in Plate 5 , but $\mathscr{V}$ continues to dominate, and it sustains surface warming into February 1998.

The cool SSTAs also have different causes in each region. In the western region (Figure 4b), they are due entirely to zonal advection of cooler waters from the eastern ocean, the other terms tending to warm the ocean. In the eastern region (Figure 


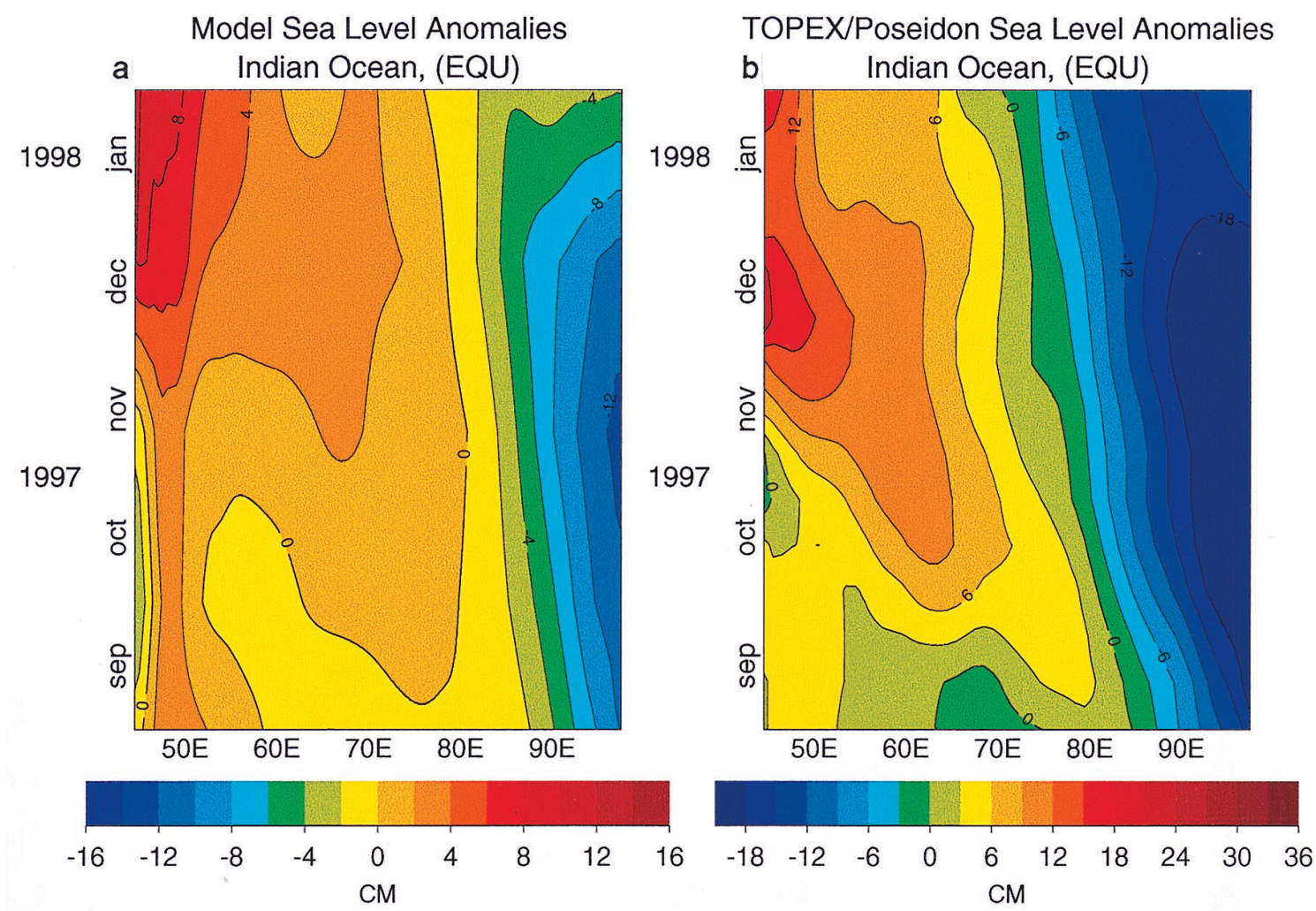

Plate 4. (a) Model and (b) TOPEX sea level anomalies along the equator for September 1997 through January 1998. Note that the color scales are different for Plates 4a and 4b.

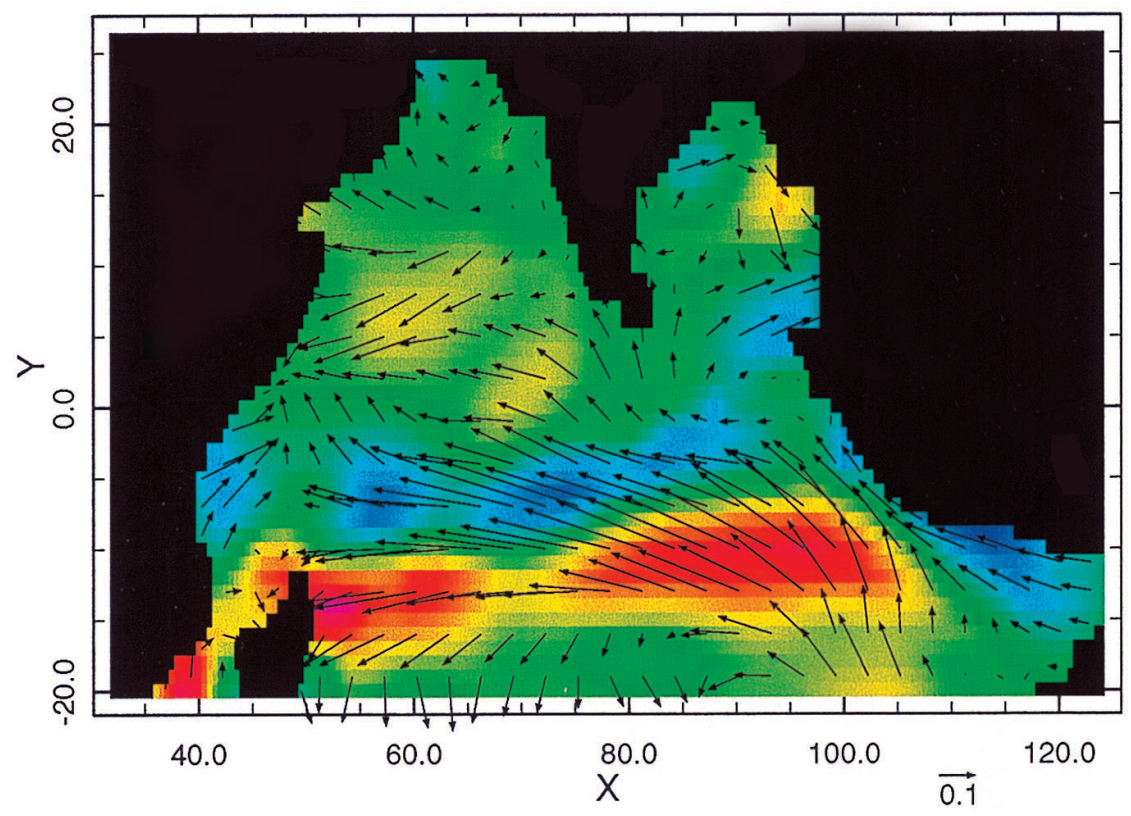

SPDA, TXA, TYA:Jan-Feb 1998

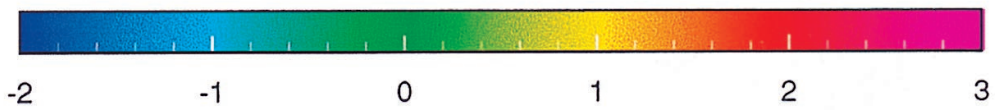

Plate 5. Anomalies of wind-speeds (colors; $\mathrm{m} \mathrm{s}^{-1}$ ) and wind stresses (vectors, dynes $\mathrm{cm}^{-2}$ ) for JanuaryFebruary 1998. 


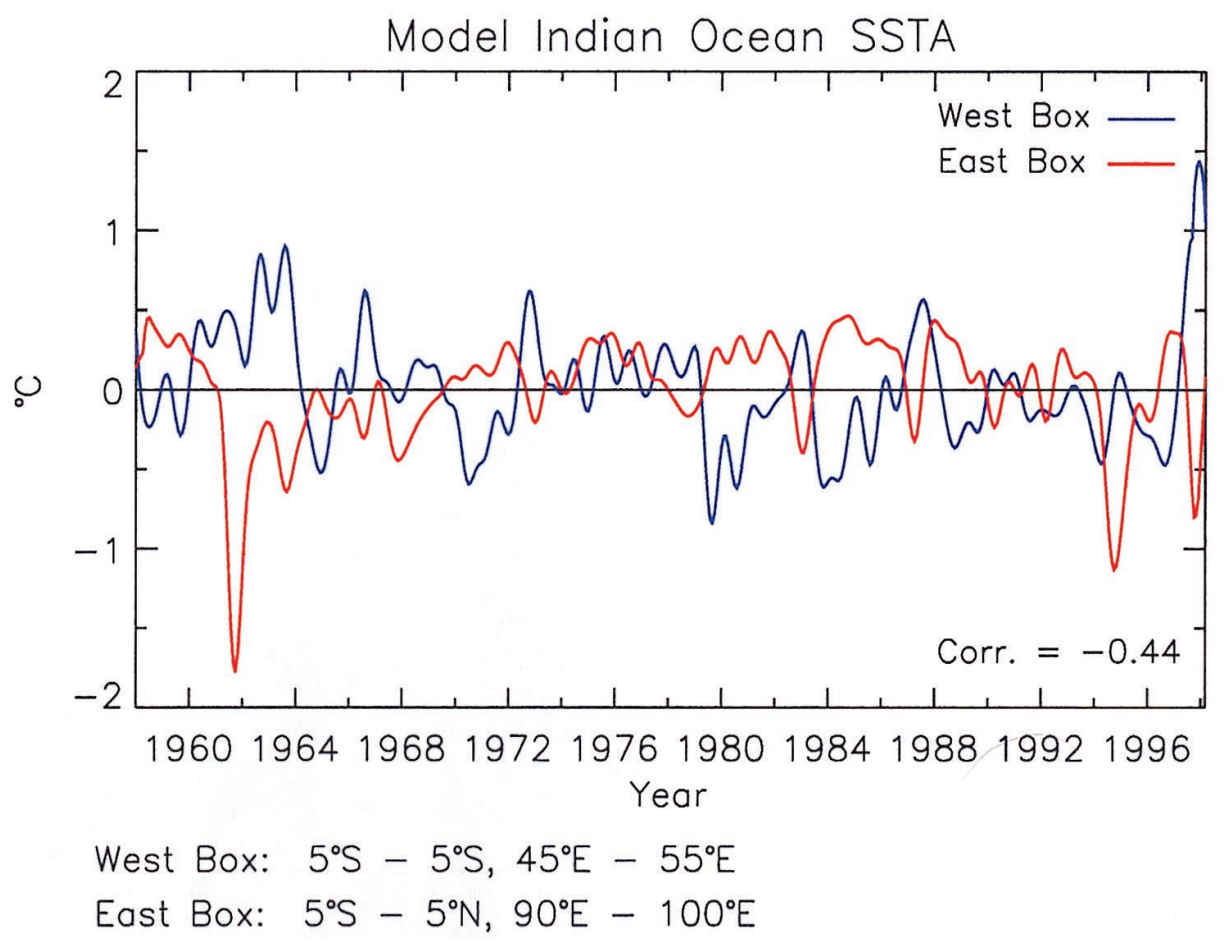

Plate 6. Time plots of SST Anomalies for 1958-1997. Extreme cold anomalies of more than $1^{\circ} \mathrm{C}$ occur in 1961, 1994 and 1997. Weaker events occur regularly throughout the record.

4c) they are caused by strengthened entrainment $\mathcal{W}$ throughout the summer and are sustained (and strengthened) during the fall by zonal $\mathcal{U}$ and meridional $\mathscr{V}$ advection. The cooling ends when these terms begin to weaken in November as the driving winds reduce in strength. Thus these three boxes were all within the v-shaped warm SST region, but the warming was ostensibly caused by different oceanic processes.

\subsection{Other Events}

3.3.1. Time series, correlations, and EOFs. Plate 6 shows SSTAs from the control run for the entire time span of the integration, averaged over the eastern $\left(90^{\circ}-100^{\circ} \mathrm{E}, 5^{\circ} \mathrm{N}-5^{\circ} \mathrm{S}\right)$ and western $\left(45^{\circ}-55^{\circ} \mathrm{E}, 5^{\circ} \mathrm{N}-5^{\circ} \mathrm{S}\right)$ equatorial IO. It is clear that neither the eastern cooling nor the western warming is unique to 1997 . There are two other extreme events in the record in which the cooling was $>-1^{\circ} \mathrm{C}$ in 1961 and 1994 , and a number of events with anomalies of the order of $-0.5^{\circ} \mathrm{C}$. Moreover, significant warm episodes in the western IO tend to occur together with the strong cool eastern events, the correlation between the eastern and western time series in Plate 6 being -0.44 , which is statistically significant at $90 \%$ confidence level. Plate 7 plots SSTAs in the eastern equatorial IO (averaged over $90^{\circ}-100^{\circ} \mathrm{E}, 5^{\circ} \mathrm{N}-5^{\circ} \mathrm{S}$ ) together with anomalies of equatorial zonal wind stress $\left(65^{\circ}-85^{\circ} \mathrm{E}, 5^{\circ} \mathrm{S}-5^{\circ} \mathrm{N}\right)$ and meridional winds off Sumatra $\left(85^{\circ}-100^{\circ} \mathrm{E}, 10^{\circ} \mathrm{S}-0^{\circ} \mathrm{N}\right)$. The correlations between SSTA and winds are very high $(0.83$ and -0.66 , respectively). Finally, the correlation between equatorial zonal wind stress and thermocline depth anomalies averaged in the eastern equatorial region is 0.7 , an indication that remote forcing by equatorial Kelvin waves is acting in all events in addition to local Ekman pumping.

These significant correlations suggest that anomalous SSTA and wind fields associated with all IO events have similar structures. To confirm this idea, we analyzed the first EOFs for SSTA and wind stresses for the entire period of the control run (not shown). Not surprisingly, the structures of the EOFs were strikingly similar to the SSTA and wind anomaly patterns in Plate 2. To ensure that the wind pattern is really associated with the dominant mode of SST variability, we carried out multivariate EOF analyses for SST and wind stresses. The first mode of the combined EOF is shown in Plate 8, which clearly confirms the fact that model SSTAs are coupled to the wind pattern for all such events.

3.3.2. Natural mode of oscillation. The similar structure of all IO events suggests that they are a natural mode of oscillation in the IO, easily excited in a variety of ways. One of those ways is forcing by climatic events external to the IO, the prime example of which is ENSO. Indeed, note in Plate 6 that many of the stronger coolings occurred during ENSO years (e.g., 1972-1973, 1982-1983, 1986-1987, 1991-1992, and 19971998). Moreover, 1994 was arguably a moderate ENSO year, and there was a severe Indonesian drought in 1961, usually a certain indicator of ENSO. (Apparently, 1961 was an instance where ENSO-like conditions prevailed only in the western basin [Flohn, 1986].) The relationship with ENSO is evidenced by significant correlations with the Southern Oscillation Index (SOI), with correlations between zonal and meridional wind anomalies and the SOI attaining values of 0.57 and -0.51 , respectively, in the region $0^{\circ} \mathrm{N}-10^{\circ} \mathrm{S}, 90^{\circ}-105^{\circ} \mathrm{E}$. A likely causal link between the IO events and ENSO is via the atmosphere [Venzke et al., 1997].

On the other hand, the SOI correlations are not that large because many of the events do not occur with ENSO, and even if they do, they do not occur with the same amplitude. Latif and Barnett [1995] carried out several uncoupled and hybridcoupled model experiments to demonstrate that while the air- 


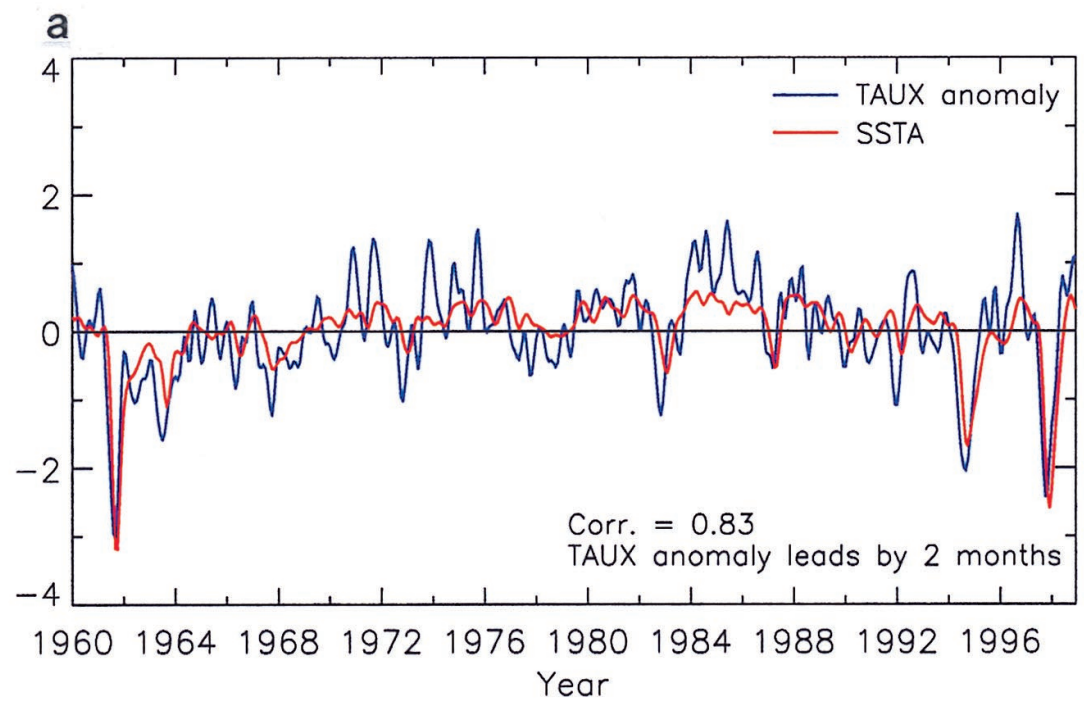

TAUX anomaly region: $5^{\circ} \mathrm{S}-5^{\circ} \mathrm{N}, 65^{\circ} \mathrm{E}-85^{\circ} \mathrm{E}$

SSTA region: $5^{\circ} \mathrm{S}-5^{\circ} \mathrm{N}, 90^{\circ} \mathrm{E}-100^{\circ} \mathrm{E}$

b

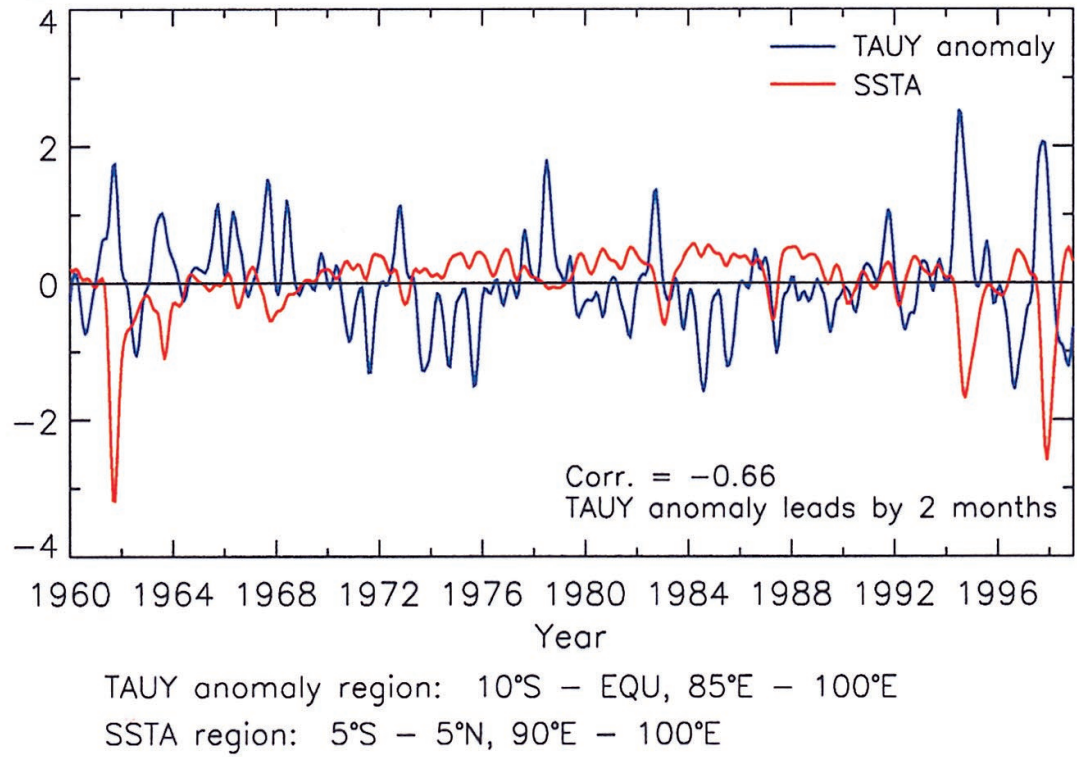

Plate 7. Correlations of SST and wind stress anomalies over (a) $5^{\circ} \mathrm{S}-5^{\circ} \mathrm{N}, 90^{\circ}-100^{\circ} \mathrm{E}$ and $5^{\circ} \mathrm{S}-5^{\circ} \mathrm{N}, 65^{\circ}-85^{\circ} \mathrm{E}$, respectively, and (b) $5^{\circ} \mathrm{S}-5^{\circ} \mathrm{N}, 90^{\circ}-100^{\circ} \mathrm{E}$ and $10^{\circ} \mathrm{S}-0^{\circ} \mathrm{N}, 85^{\circ}-100^{\circ} \mathrm{E}$, respectively. SST anomalies over eastern equatorial Indian Ocean show a very high correlation with zonal wind anomalies over central equatorial region, indicating that remotely forced Kelvin waves affect eastern coastal regions.

sea interactions in the IO are weaker than those in the Pacific, they do contribute significantly to the local SST variability. Thus the ENSO teleconnections are often enhanced by local air-sea interactions. These properties suggest the possibility that anomalous events are also amplified by, or even result from, ocean-atmosphere interactions internal to the IO. Consider the following scenario. Suppose that cool SSTAs appear in the eastern ocean, where they initiate an eastward shift of Indonesian convection. This shift allows organized convection to develop in the western ocean, establishes equatorial easterlies, sets off the oceanic events discussed in this paper, and hence leads to an intensification of the eastern cooling. Such a positive feedback mechanism (essentially the same one proposed by Bjerknes [1969] to explain El Niño) has been sug- gested as an explanation for the 1961 rain event [Reverdin et al., 1986; Kapala et al., 1994]. Reverdin et al. [1986] also point out that negative (positive) cloud anomalies associated with cold (warm) SSTA during such events most likely imply coupled interactions.

\section{Summary and Conclusions}

In our paper we have used an ocean model to examine the structure of interannual variability in the IO from 1958-1997, focussing on the intense 1997-1998 event. The model simulation captures the eastern equatorial and coastal cooling during October-December 1997 and the rapid warming by January 1998. The model warmings in the western equatorial region 


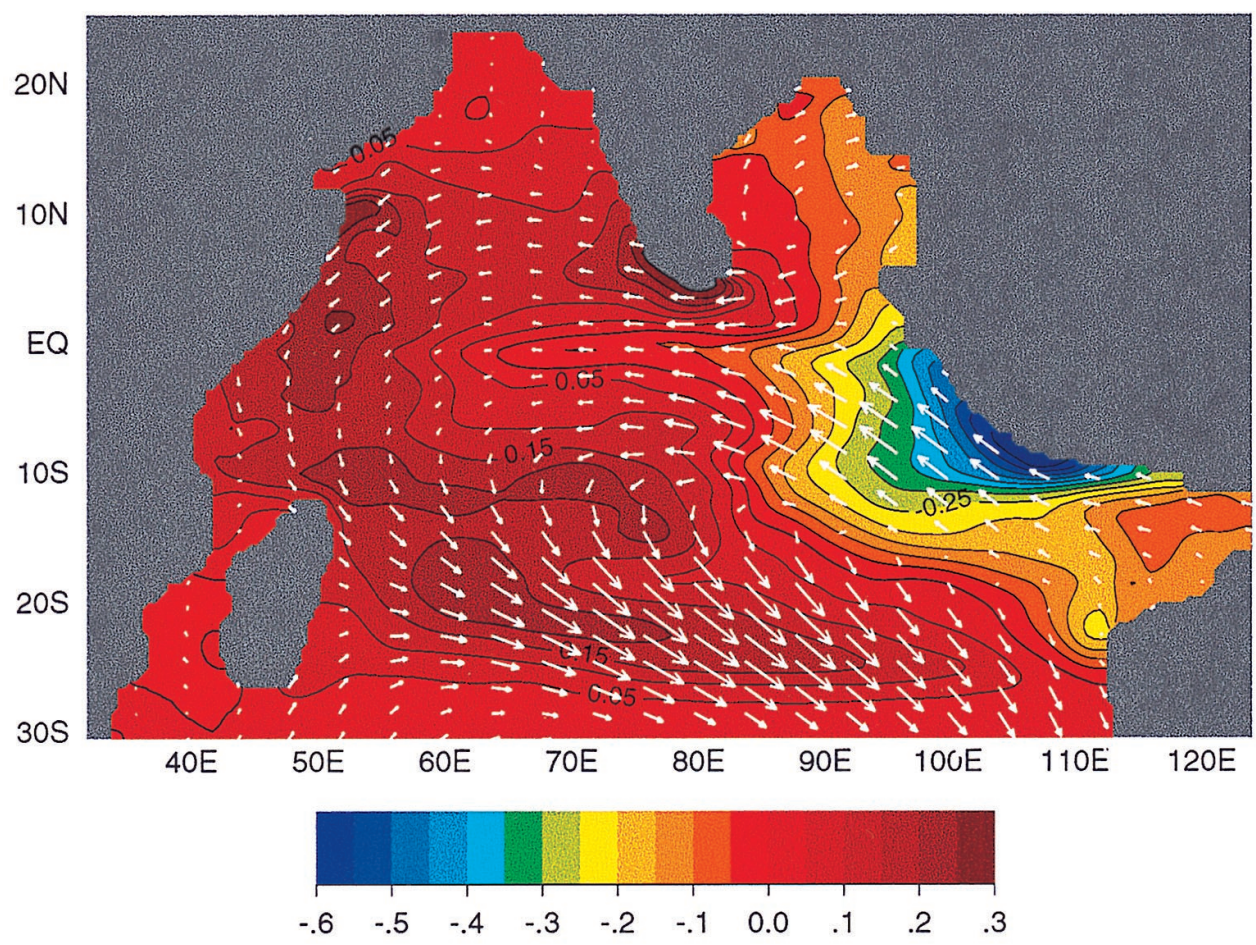

Plate 8. Combined first empirical orthogonal function (EOF) of the anomalies of model SST (1958-1997; color) and NCEP wind stresses show that the spatial pattern is strikingly similar to the SST anomalies and wind stress anomalies in Plate 2.

and the southern tropical IO are also in good agreement with Reynolds SSTA.

It is shown that equatorial easterly wind stress anomalies produced eastward Kelvin waves that raised the thermocline off the Sumatran coast. Strengthened alongshore winds enhanced surface cooling by driving stronger upwelling there, which persisted till the end of 1997. The rapid collapse of the winds, the resultant reduction in latent heat losses, and the shallowing of the mixed layer led to elimination of the cold SSTAs by February 1998. Away from the coast in the eastern equatorial region $\left(75^{\circ}-85^{\circ} \mathrm{E}, 5^{\circ} \mathrm{S}-5^{\circ} \mathrm{N}\right)$, advection played an important role in both the warming during May-July 1997 and the cooling during August-November 1997. The coastal regions were dominated by entrainment cooling during most of 1997. Wind speed dropped to near zero by late 1997 and early 1998, which resulted not only in the shallowing of the mixed layer but also in a reduction in latent heat losses. The negative SSTAs were replaced by near-zero or slightly positive SSTAs by February 1998 in the eastern part of the basin.

The western equatorial region underwent surface warming from May 1997 onward, with peak SSTAs of nearly $2^{\circ} \mathrm{C}$ by February 1998. A weaker Southwest Monsoon resulted in initial warming due to anomalous meridional advection and reduced entrainment cooling. The net heat flux anomalies remained negative and appeared to be a negative feedback to surface warming. Horizontal mixing and an incident downwelling Rossby wave seem to have been crucial in the model for sustaining the warming during late 1997 and early 1998 . The amplitude of the Rossby wave in the model is nearly $40 \%$ weaker than in TOPEX/Poseidon data, however, indicating that the model thermocline may be shallower than in reality. This discrepancy may have led to an underestimation of the role of local processes in the equatorial warming during Janu-
ary-February 1998. The western southern tropical IO experienced a warming from September 1997 onward, with peak SSTA of over $1^{\circ} \mathrm{C}$ in February 1998. Anomalous meridional advection and reduced mixed layer entrainment were largely responsible for the warming with some contribution from net heat flux during fall. The warming in the model simulation does not commence until October 1997, fully 2 months later than the observed warming. The eastern part of the southern tropical IO was warmer by $\sim 0.5^{\circ} \mathrm{C}$ during January-February 1998, mainly because of weaker winds and reduced latent heat loss.

An empirical orthogonal function (EOF) analysis of the model and Reynolds SSTA shows that the spatial pattern of the first model is remarkably similar to the patterns observed during 1961, 1994, and 1997. It is thus possible that the anomalous events during these years represent amplifications of a coupled IO mode. The forces, either internal or external, that amplify the natural mode remain to be identified, especially the processes that initialize what may potentially be positive feedback from the IO to the atmosphere above it. Within the IO region the connection to ENSO appears to be largely through the atmosphere via shifts in the Walker Circulation and associated radiative and wind-forced evaporative changes [Venzke et al., 1997]. There is, however, also an oceanic connection through changes in the Indonesian Throughflow transport [Meyers, 1996], which have large-scale, dynamic, and thermodynamic effects on IO circulation [Murtugudde et al., 1998a].

In conclusion, while we have not answered all possible thermodynamic and dynamic questions, we have analyzed, in detail, the oceanic processes that accompany IO events such as the one observed in 1997-1998. In a purely wind-driven model such as ours it is not possible to determine with certainty if 
positive feedback is active in the IO events. Experiments with coupled models that are able to simulate the events will be required to confirm the idea.

Acknowledgments. The authors wish to thank Stuart Godfrey and several members of the CLIVAR Monsoon Panel for very insightful discussions. We deeply appreciate the assistance of James Beauchamp with some of the analyses and figures. We are indebted to Jim O'Brien for allowing us access to the FSU computational facilities. RM was partially supported by NASA grants RTOP 622-32-51-20 (TRMM) and 621-55-24 (TOPEX Extended Mission) for which he is extremely grateful. JPM was supported by NSF grant OCE-94-16098, ONR contract N00014-97-1-0077, and the Frontier Research System for Global Change through its sponsorship of the International Pacific Research Center (IPRC). AJB would like to acknowledge NASA grant 578-2103 .

\section{References}

Birkett, C., R. Murtugudde, and T. Allan, Indian Ocean climate event brings floods to East Africa's lakes and Sudd Marsh, Geophys. Res. Lett., 26, 1031-1034, 1999.

Bjerknes, J., Atmospheric teleconnections from the equatorial Pacific. Mon. Weather Rev., 97, 163-172, 1969.

Chen, D., L. M. Rothstein, and A. J. Busalacchi, A hybrid vertical mixing scheme and its application to tropical ocean models, J. Phys. Oceanogr., 10, 2156-2179, 1994.

Flohn, H., Indonesian droughts and their teleconnections, Ber. Geogr. Stud., 20, 251-265, 1986.

Kalnay, E., et al., The NCEP/NCAR 40 year reanalysis project, Bull. Am. Meteorol. Soc., 77, 437-471, 1996.

Kapala A., K. Born, and H. Flohn, Monsoon anomaly or an El Niño event at the equatorial Indian Ocean? Catastrophic rains 1961/62 in East Africa and their teleconnections, paper presented at Proceedings of the International Conference on Monsoon Variability and Prediction, World Meteorol. Org., Trieste, Italy, 1994.

Latif, M., and T. Barnett, Interactions of the tropical oceans, J. Clim., 8, 952-964, 1995.

Levitus, S., Climatological atlas of the world ocean, NOAA Prof. Pap. 13, U.S. Govt. Print. Off., Washington, D. C., 1994.
Lukas, R., and E. Lindstrom, The mixed layer of the western equatorial Pacific, J. Geophys. Res., 96, 3343-3357, 1991.

Meyers, G., Variation of Indonesian Throughflow and the El NiñoSouthern Oscillation, J. Geophys. Res., 101, 12,255-12,263, 1996.

Murtugudde, R., and A. J. Busalacchi, Salinity effects in a tropical ocean model, J. Geophys. Res., 103, 3283-3300, 1998.

Murtugudde, R., and A. J. Busalacchi, Interannual variability of the dynamics and thermodynamics of the tropical Indian Ocean, J. Clim., 12, 2300-2326, 1999.

Murtugudde, R., R. Seager, and A. Busalacchi, Simulation of the Tropical Oceans with an ocean GCM coupled to an atmospheric mixed layer model, J. Clim., 9, 1795-1815, 1996.

Murtugudde, R., A. J. Busalacchi, and J. Beauchamp, Seasonal to interannual effects of the Indonesian Throughflow on the tropical Indo-Pacific basin, J. Geophys. Res., 103, 21,425-21,441, 1998a.

Murtugudde, R., A. J. Busalacchi, and J. Beauchamp, Indonesian Throughflow and ENSO: Indo-Pacific waves from TOPEX/ Poseidon, paper presented at Joint TOPEX/Poseidon Jason-1 Science Working Team Meeting, NASA, Keystone, Colo., 1998b.

Murtugudde, R., S. Signorini, J. Christian, A. Busalacchi, C. McClain, and J. Picaut, Ocean color variability of the tropical Indo-Pacific basin observed by SeaWiFS during 1997-1998, J. Geophys. Res., 104, 18,351-18,366, 1999.

Reverdin G., D. Cadet, and D. Gutzler, Interannual displacements of convection and surface circulation over the equatorial Indian Ocean, Q. J. R. Meteorol. Soc., 112, 43-67, 1986.

Venzke, S., M. Latif, and A. Vilwock, The coupled GCM ECHO-2, II, Indian Ocean response, Rep. 246, Max-Planck-Inst. für Meteorol., Hamburg, Germany, 1997.

Xie, P., and P. Arkin, An intercomparison of gauge observations and satellite estimates of monthly precipitation, J. Appl. Meteorol., 34, 1143-1160, 1996.

A. J. Busalacchi, Laboratory for Hydrospheric Processes, NASA Goddard Space Flight Center, Greenbelt, MD.

J. P. McCreary Jr., International Pacific Research Center, University of Hawaii, Honolulu, HI.

R. Murtugudde, ESSIC, University of Maryland, College Park, MD 20742. (ragu@barolo.gsfc.nasa.gov)

(Received April 16, 1999; revised September 30, 1999; accepted October 25, 1999.) 